\title{
A Multi-methods Approach in Communication Studies: autoethnography meets qualitative interviews and netnography
}

Un enfoque multimétodo en los estudios de comunicación: la autoetnografía, las entrevistas cualitativas y la netnografía

\author{
Shiyu Zheng. University of Warwick, United Kingdom \\ $\mathrm{PhD}$ researcher on Media and Communication in the University of Warwick. She has \\ been awarded a Warwick University Scholarship award and a full scholarship for \\ overseas PhD students from Chinese National Government. \\ ORCID: https://orcid.org/0000-0001-9468-8368
}

Artículo recibido: 16/11/2019 - Aceptado: 23/12/2019

\begin{abstract}
:
This article developed a multi-methods approach in the particular branch of Communication Studies (fandom studies) to understand transcultural fans' engagement. It has creatively deployed three research methods to unpack the Chinese fans of a British TV series- Sherlock. Research methods of autoethnography, netnography and qualitative interviews have been largely employed to test the loyalty of the author as an acafan (an academic/scholar who is also a fan), Chinese fans' online activity and fans' self-disclosure as a self-claimed fan. The multi-methods worked effectively to help draw the conclusion that a significant percentage of self-claimed fans do not qualify as fans in the sense defined by the relevant existing literature. The creative combination of three methods greatly facilitated the future research of fan studies to identify fans as a focal point of the research.
\end{abstract}

Key words:

Multi-methods approach; Autoethnography; Netnography; Qualitative interviews

\section{Resumen:}

Este artículo expone un enfoque multi-método en la rama específica de los estudios de comunicación sobre el fenómeno fandom para entender el engagement con fans transculturales. Así, se han desarrollado tres métodos de investigación para analizar a los fans chinos de la serie de televisión británica Sherlock. La autoetnografía, la netnografía y la entrevistas cualitativas se han empleado en gran medida para probar la lealtad del autor como acafán (un académico que también es fan), la actividad online de los fans chinos y la actividad divulgadora de los que se autoproclaman como fans. Estos distintos métodos nos permiten llegar a la conclusión de que un porcentaje significativo de los que se autoproclaman fan, no lo hacen en el sentido estricto utilizado por la literatura existente. La combinación de los tres métodos facilita 
enormemente las futuras investigaciones sobre los fans, ubicándolos en el punto central de la investigación.

\section{Palabras clave:}

Enfoque multimétodo; Autoetnografía; Netnografía; Entrevistas cualitativas

\section{Introduction}

Communication research has been explored by different scholars to a large extent. As a branch of communication research, fan studies have not been fully exploited in terms of research methodology. This is mainly because of the nature of the discipline. As Evans and Stasi (2014, p.6) explained, "fan studies is located at an inherently interdisciplinary space, with both bridges and divides between those positioned across the humanities and social sciences". Scholars from disciplines such as literature studies, audience research, sociology, film studies, TV studies, media and culture studies, as well as psychology etcetera have been involved in fan research for quite a long time. Due to the interdisciplinary nature of fan studies, Ford (2014) described fan studies as grappling with an "undisciplined" discipline and the research methods for fans studies were various including the "disciplined attendant methodological perspectives" (Evans \& Stasi, 2014, p.7) such as quantitative, qualitative, practice-based, online, offline, archival, psychological and community-centred methods, etcetera.

Among the different research methods of fan studies, how to methodologically define a "fan" identity is of great significance as it is the basis of understanding fans and their practices (Evans \& Stasi, 2014). The proposed research question is how Chinese fans have transculturally engaged themselves in the British TV series. Under the circumstance of transcultural fandom, determining a fan requires more methodological techniques as it crosses over national boundaries and major cultural barriers of communication. Therefore, the research methodology was set up in the digital media environment as the author engaged with Chinese fans from the UK and read Chinese fan interpretations of a UK text. In order to better understand the transcultural fandom communication in this research, the author will mainly adopt three research methods for analysis in detail, which are autoethnography, netnography and qualitative interviews.

\section{Methodology}

\subsection{Engagement and intimacy: autoethnography}

A majority of fan researches have been conducted by the acafan (Jenkins, 2006) who are both fans as well as academic scholars/researchers. The author has been in the online group of Sherlock fans for quite a while and the proximity and intimacy the author shared with the project is the main reason for using autoethnography research. As a research method, "autoethnography combines characteristics of autobiography and ethnography. When writing an autobiography, an author retroactively and selectively writes about past experiences” (Ellis et al., 2011, p.274). It is best 
understood as "an autobiographical genre of writing and research that displays multiple layers of consciousness, connecting the personal to the cultural” (Ellis \& Bochner, 2000, p.739). As an insider, the author has engaged in the online practices regularly and as a researcher, she has frequently noticed fans' daily activities. It has become a personal habit for her to lurk at social media sites every week and browse through fans' endless gossips of every tiny aspect of Sherlock and "discussion of various social and personal issues" (Yang, 2009, p.528). The author has personal engaged experience about behavior of the fans of Sherlock so that autoethnography benefits the research as the author part of being the research object. There is no doubt about the close relationship between the research object and the author in autoethnography, according to Ellis et al.'s (2011) definition. This study will contextualize autoethnography to retroactively and selectively trace back the personal story about the author's engagement of Sherlock.

\subsection{Online observation and engagement- netnography}

With regard to Chinese fans of Sherlock, they are distant fans from another culture, language and even nation, who are the transcultural fans. How to target and approach fans is the first priority. Online sampling via social media sites is a more direct and effective way to find out them as fans are distributed in different regions. The author has been in five online fan groups ${ }^{1}$ for more than two years since 2017 (two of them ${ }^{2}$ for over four years), it is of great advantage to be engaged in some groups of Chinese fans via internet or featured social media sites in China. This way was coined as the methodology of "netnography" by Robert Kozinets (2010) who referred to "a way into understanding the social activities and encounters of individuals as they are found on the internet" (p.1). Netnography was "the ethnography of online groups, studies complex cultural practices in action, drawing our attention to a multitude of grounded and abstract ideas, meanings, social practices, relationships, languages and social systems" (Kozinets, 2010, p.25). Kozinets (2010) argued that social scientists were no longer able to "adequately understand many of the most important facets of social and cultural life without incorporating the Internet and computer-mediated communications into their studies" (p.3). These were also the reasons why the author used netnography for this research. This research method (netnography) was adopted from a perspective afforded to the author, in part, by the virtue of being part of the online fan group of Sherlock. With the rapid development of digital media technologies and fast-paced life, more fans tend to more engage themselves online instead offline. Over the past years of being a member of the fan groups, the author realised that there were fewer offline activities organized by the fan members. More and more fan peers joined the groups via virtual communities. Meanwhile, the long-term British TV series with long period intervals such as Doctor Who and Sherlock were not allowed to be broadcasted on the main TV channels in China. The most general way for fans to watch the TV is from the internet streaming video platforms. Therefore, netnography also applies to the transcultural condition of TV broadcasting and watching, as well as fan practices such as comments, posts, etcetera, particularly for the distant fan researcher.

1. Douban, Zhihu, Bilibili, Youku and Post Bar

2. Bilibili and Post Bar 


\subsection{Qualitative Interview}

\subsubsection{Obtaining interviews: Netnography \& snowballing sample}

Traditional research methods used in Communication Studies have employed interviews frequently (Hansen \& Machin, 2019). Combining qualitative interviews with online observation is by no means a new or innovative approach in the humanities and social sciences though its application in Communication Studies is more infrequent. However, qualitative interviews indeed lay the ontological and epistemological foundation of this research, as it told about why or how the relationship between audience and the media could be (Hansen \& Machin, 2019). In this research, the qualitative interview data research has heavily relied on the analysis of identifying fan object and their practices, including the ways, reasons, motivation and incentives of their engagement. Therefore, the research method of qualitative interview has been elaborated in great detail. The researcher conducted interviews in depth that were obtained in a number of different ways. The way the author approached interviewees can be seen as a part of the personal developed method as it closely connects with the author's aca-fan identity in different digital sites for past two years. As mentioned above, digital/social media serves as the platform for the author to approach interviewees in the first instance. The explosion of social media sites brings with it "exciting opportunities" for studying fan communities (see e.g. Pullen, 2004; Hine, 2011) as well as the interactive process by which new media technologies are becoming an integral part of and being used for communication and "meaning-making" (Kim, 2016). Based upon the important role of social media, the author firstly obtained the interviews from the aforementioned social media sites. Social media has been referred to the information sites (Diga \& Kelleher, 2009), or a set of information technologies which facilitated interactions and networking (Kapoor et al., 2017; Oestreicher-Singer \& Zalmanson, 2013). Boyd and Ellison (2008) defined social media as the websites that allowed profile creation and visibility of relationships between users and web-based applications and provided functionality for sharing, relationships, group, conversation and profile (Kietzmann et al., 2011). Thus the author made full use of this "common denominator" (Wolf et al., 2018, p.3) of social media to observe members' posts as well as their personal profile in order to approach the targeted interviewees and then contact them initially via the functionality of private conversation/messages.

Those who had frequent posts online were the first that attention was paid to. Over these five sites, Douban and Post Bar have relatively small base of posts while other three sites have larger number of users, which means post selection kills great time. Therefore, the author adopted Python to find out the top 20 posts with the most clicks of review on each site and then approach the "uploader" or "author" of the post as a stranger who they had not been aware of.

Though social media facilitated the initial contact with the online interviewees, Chinese fandom of Sherlock is not only limited to the Internet-based sphere and the interview sample needs to be expanded furthermore. In order to have more interviewees, snowballing sampling is a key to find out more fan peers. Bertrand and Hughes (2017, p.68) highlight, "snowballing sampling is [...] you find one person, who directs you to 
another, who in turn directs you to still others. This allows you to tap into kinship and friendship networks, which may be part of what you are studying." Zhang and Mao (2013), Sandvoss and Kearns (2018) are the representative scholars who made full use of snowballing sampling to reach more fan interviewees. Meanwhile, over the process of snowballing sampling, new opportunities may arise so that Bertrand and Hughes (2017) suggest taking advantages of "opportunistic sampling” (p.68) to direct to more fruitful sources and date for collection. The author has made full use of the opportunistic sampling principle to develop more interviews based on the initial contacts of the fan object from the above five digital media sites. She then asked the initially approached fan interviewees to recommend more peers who had also showed great interest in Sherlock. Apart from their recommendations, the author focused on the comments under the top 100 posts to seek for those who liked to leave comments. By this method, 30 interviewees were obtained and meanwhile, the new opportunities of discovering loyal fans may arise over the snowballing sampling that would help to reach more counterparts over the process. However, due to the low activity and enthusiasm of fan practices after last series (only 150 posts have been uploaded on one of the digital media sites- Douban after last series in 2017), as well as the discursive engagement within fan groups in reality, the snowballing process costs time, especially in approaching the fans who seldom distinguished themselves on the digital applications.

\subsubsection{Structure design: semi-structure interviews}

After determining the interviewees, the interview content is of great significance. In order to make the interviews open-minded and interviewee-oriented, the semi-structured interview technique was chosen. Compared to quantitative research methods such as semi-structured survey, "[s]emi-structured individual interviews or semi-structured group interviews are approaches which allow the researchers a potentially much richer and much sensitive type of data on the dynamics of audiences and their relations to media” (Hansen \& Machin, 2019, p.222). Though semi-structure interviews were not costly and not burdened by the resources, it was a time consuming and demanding process, which required interviewers' full preparation. The author developed a consent form, given to the interviewees, which had a detailed introduction of the project as well as the list of questions that were to be asked. This made the interviews aware of the questions early allowing proper ethical approval to be obtained. In the consent form, the open-ended questions were labelled out in case of possible answers involving personal privacy. This consists of different sets of questions as Corbin and Strauss (2008) emphasized and the semi-structured interviews were always in-depth interviews "where the respondents have to answer preset open-ended questions” (p.61). Semi-structured, in-depth interviews were utilized extensively as interviewing format with an individual or with a group in sociological research. It was based on "a schematic presentation of questions or topics that would need to be explored by the interviewers" (Crabtre \& DiCicco-Bloom, 2006: 314). Crabtre and DiCicco-Bloom (2006) suggested interview guides to serve the useful purpose of exploring many respondents through more systematic and comprehensive questions as well as to "keep the interview focused on the desired line of action" (p.314-5) so that the use of interview time was optimised. In the planned interviews, this was what the author designed to achieve, that is beginning with preset questions and moving to open-ended questions over the interview. The 
interview comprised of core questions such as fan identity recognition and fan loyalty judgment, followed by many associated questions related to the central question with open answers such as the diversity of interviewees' practices, degree of engagement, online and offline activity/practice organisation etcetera, which in turn, further improve the "interview guide" (Creswell \& Poth, 2017, p.133).

\section{Discussion}

\subsection{Autoethnography analysis - a dormant fan}

The selection of research method is the first phase for better unpacking the transcultural fandom in China while how to analyze data is the second and more important phase for complementing the research. This section will discuss the process of data collection and analysis in great detail. More than the pure self-reflection of being a fan for the research method of autoethnography, the author adopted Anderson's (2006, p.376) suggestion of "analytic" autoethnography to commit to an analytic research agenda focused on improving theoretical understandings from "personal" to "evocative" (p.374). Anderson (2006) emphasised the existence and visibility of the researcher in the research setting, as well as the improvement of "theoretical understandings of broader social phenomena” (p.374). His principles helped the author to better understand the role of herself in the research. This research aimed to understand the role of transcultural fans and their circumvention over the particular censorship to manage communal and fan identities that extend beyond the Chinese media landscape. The author has been one of the researched fan objects influenced by both British TV and Chinese media and cultural environment. Reed-Danahay (1997) explained autoethnography as "an ethnography of one's own group", or a genre of "autobiographical writing that has ethnographic interest" (p.2). This partially reveals fact of this research methodology while not intaking the impacts of other "hindsight". The author did not live through the experience of being a member/ fan solely to make it part of the research. Rather, her experience was assembled using "hindsight" (Bruner, 1993; Denzin, 1989; Freeman, 2004). Over the process of conducting autoethnography, the author interviewed other peers as well as consulting with texts like comments, journals, images, videos and recordings, etc. to help recall the memories herself (Delany, 2004; Didion, 2005; Goodall, 2006; Herrmann, 2005). It is not a private and personal story-telling process but includes "interactive interviews" (von Kardorff \& Schonberger, 2010, p.59). Over this process, the author gradually noticed herself not being a real fan as her interests faded away very quickly. She did not voluntarily choose to serve as an active fan, instead she was more dormant so as to be a lurker for observing others' posts. In this way, the author made a cautious and conscious decision to define herself as a fake fan literally.

\subsection{Netnography - fans not to be a fan}

As mentioned above, the author chose to use netnography because she had been a member of five digital media sites based upon the interests of Sherlock. Because of the necessity of conducting the research, the author consulted active fan members on these 
digital media sites for Sherlock engagement. Referring to group members' introduction, the author targeted her researched fan object from the largest fan groups on different social media to observe their practices as they were relatively large sample, which was more representative. These five digital media sites are of great popularity among Chinese fans, according to the number of participants and members. In order to determine the timescale of fan practices on these sites, the author referred to Bertrand and Hughes' (2005, p.68) "purposive sampling” to narrow down the duration specifically. As Bertrand and Hughes (2005, p.68) introduced, purposive sampling is "on the basis of earlier experience" to confirm or disconfirm cases, which then become "purposive sample”. From the past two years' online observation, the degrees of fan liveness (e.g. enthusiasm) of Sherlock was not as high as those of Chinese local TV series. Fewer scholars in China and outside China have paid attention to the phenomenon of the fans' transfer and lifespan. The author found out how Chinese fans of Sherlock engaged themselves when there was a significant cultural barrier and a long interval time between series- they felt depressed, passive and had low enthusiasm and they even stopped doing more practices on Sherlock after the series ended. As is shown in the Figure 1, only 9 posts were uploaded from January 2019 to June 2019. The low frequency of posts presented fans' disengagement from Sherlock.

In order to comprehensively analyse this phenomenon, the author ranked the top 10 posts with the most comments/likes by sites' functions and by hand as a dataset. The top 10 heated posts (including video, commentaries, etc.) respectively on each site with the most comments or clicks of views helped to do online observation as well as finding out fans' common interests and favourite topics. The author observed these $50^{3}$ posts carefully and found the low activity, low interests and low interaction of Sherlock. They were not as what Hills (2002) has defined a fan who were active, enthusiastic and passionate about their obsessed object.

Figure 1

\begin{tabular}{|c|c|c|c|}
\hline 会不会出第五季? & je t'aime & 1 & \\
\hline 有卷福的壁纸吗? & Azure & & $06-15$ \\
\hline 有没有人像我一样觉得卷福对花生感情比较多。.. & 雨粚泥香 & 132 & 06-09 2 \\
\hline 请问神夏的生肉要在哪里找呀? & 年轻人 & & 06-06 1d \\
\hline The Texts & Mrs.J & 13 & $04-1720$ \\
\hline 神探夏洛克有第五季吗? & 追索人心的深度 & 5 & 04-06 09 \\
\hline 在图书馆看到缺爷封面的杂志！有图有真相! & 白芷花楹 & 7 & 04-05 13 \\
\hline 求福华神级剪刀手章超的优酷账号和微博 & mix & 1 & $01-2701$ \\
\hline 求夏洛克的大衣牌子。。 & 小小 & 140 & $01-25$ of \\
\hline 第二季第一集死人飞机的诸多疑问, 望大神解惑。 & Tudou & 7 & $01-17$ \\
\hline 卷福太美, 不能让我一个人瞎! & 一藏荱 & 37 & \\
\hline
\end{tabular}

Screenshot: Only 9 posts was uploaded by Chinese fans in the first half of 2019 (January 2019 to June 2019) about Sherlock. From: Douban Sherlock Group, retrieved on $15^{\text {th }}$ December 2019.

3 Top 10 heated posts on one site and 50 posts in total of 5 sites. 


\subsection{Interview techniques: Self-disclosure to be a non-fan}

Fan practice is always about personal experience and engagement (Jenkins, 1992; Hills, 2005; Morimoto \& Chin, 2017). The research method of interviews highly demands the interviewees' engagement and self-disclosure. The focus on valorizing the meanings of Sherlock towards interviewees (fan object) and on highlighting fans' affective connection to Sherlock necessitates the unique style of interviews the author carried out with the participants. The author asked interviewees what Sherlock meant to them, how often they watched Sherlock, how many hours a day they watched Sherlock, how many episodes/series they have covered, how much online practice they did about Sherlock such as reading, writing, etc. This is a process of disclosing interviewees as well as their practices about Sherlock. Over this process, self-disclosure is an important technique for the qualitative interviews. As Abell et al. (2006, p.222) explained, "The issue of selfdisclosure in qualitative research is an on-going debate [...] these narratives on selfdisclosure are most usually directed toward the issue on the part of participants rather than of researcher". The degree of self-disclosure depends on the intimacy and relation between the interviewees and the interviewers, which is closely linked to the aforementioned method of autoethnography. Compared to the self-disclosure framed by professional boundaries (Caldwell, 2009), the self-disclosure of this study was more about assisting the author as a researcher in the production of meaningful knowledge of fan studies. As the autoethnography approach was deployed at its core of this research, it therefore seems more crucial to explore the author's own understanding of the topics at hand with her fellow participants. By revealing more about the author herself as a part of the fan members, she redressed the power-balance between interviewees and interviewers and got closer to the participants within the interview setting.

There is no doubt that the participants perform different degrees of self-disclosure in the interviews. In order to facilitate them to better share their stories, another technique of narrative inquiry plays a key role here. According to Clandinin and Connelly (2000, para. 3), "narrative inquiry is an umbrella term that captures personal and human dimensions of experience over time and takes account of the relationship between individual experience and cultural context". It is a means by which researchers systematically gather, analyse, and represent people's stories as told by them, which might challenge traditional and modernist views of truth, reality, knowledge and personhood (Etherington, 2013). It is also "a gentle relational methodology that has the capability to uncover what is important to the person in their situation." (Haydon et al., 2018, p.129). By using the narrative inquiry, interviewers were given enough trust to tell their life stories about the research object (Etherington, 2013) that could benefit the research from much deeper understanding and exploration of Chinese fans' motivation/reasons to take part in the Sherlock relevant practices, as well as of the significance of Sherlock towards their daily life. The identity of the author as an academic researcher and aca-fan benefited this method to a large extent, and it seems trustworthier to share personal stories to a peer instead of a researcher. Over the interviews, the fan interviewees shared their transfer of being a fan to not being a fan due to different reasons. Since the narrative inquiry requires research findings to be "presented narratively, that is, [...] engagingly for the consumer of the research" (Haydon et al., 2018: 129), the author invited interviewees to recall the memories and 
tell personal experience as the transfer went on (from being a Sherlock fan to a nonfan). As fan engagement tends to become more personal and individual (Sandvoss, 2005; Sandvoss \& Kearns, 2018), the author has attempted to discover the unique points about the different details of identity changes from interviewees. Some of them shared the personal reasons of not being a fan because they have turned their attention to other products, while some of them revealed their disappointment of Sherlock over the four series. By employing the tool of featured Chinese cultural context such as cultural understanding and Chinese values, more fans responded narratively to show the reasons of their transfer to be a non-fan based upon their educational and cultural value. The Chinese cultural and political values, the featured digital/social media environment, the fan communities/group and the fan peers led to the changes from being a fan to be a non-fan.

\subsection{Discourse analysis - fan productivity \& activities}

Fan research needed discourse analysis to understand fans' regular practices while in order to further analyse fan practices such as texts and videos, it is necessary to examine the content of their narratives. Discourse is viewed as a "socially constructed knowledge" by Fairclough (1995) and generally "treated as the broader ideas communicated by a text" (Hansen \& Machin, 2019, p.154). "The discourse can be thought of as models of the world" (Hansen \& Machin, 2019: 154), which means the condensed argument and narratives demanded (Hansen \& Machin, 2019) in sentences or paragraphs to define the discourse. Since the aforementioned five digital sites focused on different functions, the author collected and categorised the discourses by hand. Frist of all, she observed the top 10 posts on each site to see if each post had a specific discourse. Then the author marked the posts with discourses inside for discourse analysis and left the rest posts without clear hints of discourse for possible thematic analysis. The top 10 popular fan made videos uploaded on Bilibili with a clear discourse have been transcribed (subtitles) into a document as video discourse and the top 10 posts with the most comments on Youku and most answers on Zhihu have been digitally scraped into two datasets separately for textual discourse. The contents shared by fans on Douban and Post Bar of Sherlock are relatively fewer in amount. The author noticed that less than 20\% self-claimed fans tended to discuss Sherlock and the most common discourse from their interviews and posts was "Do not like Sherlock as before", which revealed the relationship between text, consumer and producer (Moores, 1993; Press \& Livingstone, 2006). By these methods, the fact that Sherlock fans in China were no longer fans any more was more apparent, as they seldom produced texts and had direct relation with the texts and producer.

\section{Conclusions}

As a string of Communication Studies, the research methodology discussion of Fandom Studies was not robust. This article proposed a multi-methods approach to analyse transcultural fans from an aca-fan's perspective. From the above analysis, it is not difficult to see that the research methods deployed in Communication and Fandom Studies were distinguished because of the speciality of the object. Under the transcultural background, the fans are more difficult to be researched and analysed than 
the fans of a single culture. This research deployed autoethnography, netnography and qualitative interviews to test if the Chinese fans of Sherlock were real fans like the existing literature has defined. Meanwhile, the multi-methods approach also articulated the complexity of the research. It showed the reasons why the author chose to use the aforementioned three methods and how these methods were implemented to achieve the purpose of data collection and research objectives. From the autoethnography, it is not difficult to see the changed attitudes of the author from Sherlock. The author tended to become a lurker with fewer activities around Sherlock while the netnography employed different digital media sites to do further observation and to find out the common attitude and psychology of fans towards Sherlock. They were no longer a real fan and the change has been managed gradually over the past two years' observation. The qualitative interview further proved the transferred identity of being a self-claimed fan that were not real fans. Less than $20 \%$ of the interviewees still showed interests to the series while their enthusiasm went down dramatically under the transcultural background with long intervals between series. From that perspective, the research effectively combined three methods to approach and reveal the research object, so that to define a new model of "fan" type that is an addition to the existing understanding of fan literally. The combination of different research methods meanwhile introduced a new logic to develop Communication Studies on fans and fandom in the transcultural contexts.

\section{References}

Abell, J., Locke, A., Condor, S., Gibson, S., \& Stevenson, C. (2006). Trying similarity, doing difference: the role of interviewer self-disclosure in interview talk with young people. Qualitative Research, 6(2), 221-244.

Anderson, L. (2006). Analytic autoethnography. Journal of contemporary ethnography, 35(4), 373-395.

Bertrand, I., \& Hughes, P. (2017). $2^{\text {nd }}$ Ed. Media research methods: Audiences, institutions, texts. London, UK: Macmillan International Higher Education.

Boyd, D. M., \& Ellison, N. B. (2008). Social network sites: Definition, history, and scholarship. Journal of computer-mediated Communication, 13(1), 210-230.

Bruner, J. (1993). The autobiographical process. Current Sociology, 43(2), 161-177.

Caldwell, J. T. (2009). Cultures of production: Studying industry's deep texts, reflexive rituals, and managed self-disclosures. Media industries: History, theory, and method, 199-212.

Clandinin, D. J., \& Connelly, F. M. (2000). Narrative inquiry. San Francisco, US: Jossey-Bass.

Corbin, J., Strauss, A. L., \& Strauss, A. (2008). Basics of qualitative research. New York, US: Sage. 
Creswell, J. W., \& Poth, C. N. (2017). Qualitative inquiry and research design: Choosing among five approaches. New York, US: Sage publications.

Denzin, N. K. (1989). Interpretive biography (Vol. 17). New York, US: Sage.

Didion, J. (2005). Miami. London, UK: Granta.

Diga, M., \& Kelleher, T. (2009). Social media use, perceptions of decision-making power, and public relations roles. Public Relations Review, 35(4), 440-442.

Ellis, C., Adams, T. E., \& Bochner, A. P. (2011). Autoethnography: an overview. Historical Social Research/Historische Sozialforschung, 273-290.

Ellis, C., \& Bochner, A. (2000). Autoethnography, personal narrative, reflexivity: Researcher as subject. Retrieved from https://www.researchgate.net/publication/254703924_Autoethnography_Persona 1_Narrative_Reflexivity_Researcher_as_Subject

Etherington, K. (2013). Narrative approaches to case studies. Last accessed, 30.

Evans, A., \& Stasi, M. (2014). Desperately seeking methods: New directions in fan studies research. Participations, 11(2), 4-23.

Fairclough, N. (1995). Media discourse. London, UK: Edward Arnold

Ford, S. (2014). Fan studies: Grappling with an 'Undisciplined'discipline. The journal of fandom studies, 2(1), 53-71.

Freeman, L. (2004). The development of social network analysis. A Study in the Sociology of Science, 1.

Goodall Jr, H. L. (2006). A need to know: The clandestine history of a CIA family. London, UK: Routledge.

Hansen, A., \& Machin, D. (2019). Media and communication research methods: Macmillan International Higher Education.

Haydon, G., Browne, G., \& van der Riet, P. (2018). Narrative inquiry as a research methodology exploring person centred care in nursing. Collegian, 25(1), 125129.

Herrmann, A. F. (2005). My father's ghost: Interrogating family photos. Journal of loss and trauma, 10(4), 337-346.

Hills, M. (2002). Fan cultures. London, UK: Routledge.

Hills, M. (2005). The pleasures of horror. London, UK: Bloomsbury Publishing. 
Hine, C. (2011). Towards ethnography of television on the internet: A mobile strategy for exploring mundane interpretive activities. Media, Culture \& Society, 33(4), 567-582.

Jenkins, H. (2006). Fans, bloggers, and gamers: Exploring participatory culture. New York, US: NYU Press.

Kapoor, K. K., Tamilmani, K., Rana, N. P., Patil, P., Dwivedi, Y. K., \& Nerur, S. (2018). Advances in social media research: past, present and future. Information Systems Frontiers, 20(3), 531-558.

Kietzmann, J. H., Hermkens, K., McCarthy, I. P., \& Silvestre, B. S. (2011). Social media? Get serious! Understanding the functional building blocks of social media. Business horizons, 54(3), 241-251.

Kim, S. J. (2016). A repertoire approach to cross-platform media use behavior. New Media \& Society, 18(3), 353-372.

Kozinets, R. V. (2010). Netnography: The marketer’s secret weapon. White paper, 113.

Morimoto, L. H., \& Chin, B. (2017). Reimagining the Imagined Community. Fandom: Identities and Communities in a Mediated World, 174.

Oestreicher-Singer, G., \& Zalmanson, L. (2013). Content or community? A digital business strategy for content providers in the social age. MIS quarterly, 591-616.

Pullen, K. W. (2004). Everybody’s gotta love somebody, sometime: Online fan community. In Web studies (pp. 80-91): Arnold.

Reed-Danahay, D. (1997). Auto/ethnography. New York, US: Berg.

Sandvoss, C. (2005). Fans: The mirror of consumption. Sussex, UK: Polity.

Sandvoss, C., \& Kearns, L. (2018). From interpretive communities to interpretative fairs: ordinary fandom, textual selection and digital media. The Ashgate research companion to fan cultures, 91-108.

Von Kardorff, E., \& Schönberger, C. (2010). Evaluationsforschung. In Handbuch qualitative Forschung in der Psychologie (pp. 367-381): Springer.

Wolf, M., Sims, J., \& Yang, H. (2018). Social media? What social media? Paper presented at the Annual Conference of the UK Academy for Information Systems, Oxford.

Yang, L. (2009). All for love: The Corn fandom, prosumers, and the Chinese way of creating a superstar. International Journal of Cultural Studies, 12(5), 527-543. 
Zhang, W., \& Mao, C. (2013). Fan activism sustained and challenged: participatory culture in Chinese online translation communities. Chinese Journal of Communication, 6(1), 45-61.

HOW TO CITE (APA 6 $6^{\mathrm{a}}$

Zheng, S. (2019). A Multi-methods Approach in Communication Studies: autoethnography meets qualitative interviews and netnography. Comunicación y Métodos | Communication \& Methods, 1(2), 196-208. doi:10.35951/v1i2.43 